Original Research Paper

\title{
Cyclic Instability of Shape-Memory Alloys in Seismic Isolation Systems
}

\author{
${ }^{1}$ Filipe Amarante dos Santos, ${ }^{1}$ Corneliu Cismasiu and ${ }^{2}$ Francisco Braz Fernandes \\ ${ }^{1}$ Department of Civil Engineering, \\ ${ }^{2}$ Department of Material Sciences, CENIMAT/I3N and Faculdade de \\ Ciências e Tecnologia da Universidade NOVA de Lisboa, Lisboa, Portugal
}

Article history

Received: $28-09-2017$

Revised: $19-12-2017$

Accepted: 05-01-2018

Corresponding Author: Filipe Amarante dos Santos Department of Civil Engineering, Ciências e Tecnologia da Universidade NOVA de Lisboa, Lisboa, Portugal

Email: fpas@fct.unl.pt

\begin{abstract}
Shape-memory alloys are being progressively introduced as kernel components in seismic retrofitting devices for civil engineering structures. In order to control the instability associated with the first mechanical cycles, a training procedure is usually implemented, which stabilizes the superelastic behavior of the alloy. This paper addresses the characterization of the cyclic behavior of an austenitic NiTi alloy with emphasis on the definition of the instability functions associated with the cumulative residual strain and the variation of the critical stress needed to induce martensite. A wide set of experimental tensile tests are performed to study the influence of strain-rate and ambient temperature on the material coefficients controlling the described functions. A numerical model for shape-memory alloys is presented, which is able to simulate the instability phenomena associated with superelastic cycling in NiTi wires. It is shown that prior stabilization by initial training may not be advantageous, since it is during the first cycles that the alloy shows greater energy dissipation capabilities.
\end{abstract}

Keywords: Shape-Memory Alloy, Superelasticity, Instability, Mechanical Cycling

\section{Introduction}

Shape-Memory Alloys (SMAs) are a unique class of metallic alloys that exhibit the ability to develop a diffusionless phase transformation in solids called martensitic transformation. This enables the material to recover from large cyclic deformations (up to $\simeq 8 \%$ ) while developing a hysteretic loop, in a process which is usually called superelasticity. This process is translated into the ability of the material to dissipate energy. Due to their high inherent damping, repeatable re-centering capabilities and relatively high strength properties, SMAs have been progressively introduced in new technological applications related with energy dissipation in civil engineering structures. Most of the applications reported in the literature are related to the seismic resistance enhancement of cultural heritage structures (Croci, 2001; Indirli et al., 2001) and to a wide range of vibration control devices, like bracing systems (Boroschek et al., 2007; Dolce et al., 2005; Zhang and Zhu, 2008; McCormick et al., 2006), base isolation systems (Shook et al., 2008; Corbi, 2003; Wilde et al., 2000), structural connections (Ocel et al., 2004; Tamai et al.,
2004) and bridge hinge restraining systems (Johnson et al., 2008; Padgett et al., 2010; Andrawes and DesRoches, 2007; DesRoches and Delemont, 2002). Although several studies have clearly demonstrated the vast potential of SMAs in vibration control, a set of undesirable effects, affecting SMAs, have an adverse impact on the performances of seismic devices based on superelastic kernel components. These effects comprise the high dependence of these materials on strain-rate, strain-amplitude, ambient temperature, time-dependent effects like stress-relaxation and strain-creep and instability due to cyclic loading (Otsuka and Wayman, 1998; Dolce and Cardone, 2001; Patoor et al., 2006; Piedboeuf and Gauvin, 1998; Vitiello et al., 2005; Montecinos et al., 2005; Beltran et al., 2011).

Cyclic loading is known to influence the superelastic behavior of SMAs in general and NiTi in particular (SaintSulpice et al., 2009). According to experimental observations made by several authors (Tobushi et al., 1991; 1998; Kan, 2009), the superelastic hysteresis is shifted to the larger strain side and to the lower stress side, with increasing number of cycles, before its full stabilization (Torra et al., 2007). Although this change is significant in 
the early cycles, it becomes less important after about 100 cycles (Nemat-Nasser and Wei-Guo, 2006). This causes the net strain produced by a given structural oscillation to be reduced, decreasing the energy dissipation capabilities of the material (Nemat-Nasser and Wei-Guo, 2006).

The key parameters defining the cyclic instability of the superelastic hysteresis are the cumulative residual strain, $\varepsilon_{p}$ and the variation of the critical stress needed to induce martensite, $\Delta \sigma$. These parameters are illustrated in Fig. 1.

The process of cumulative residual strain is explained by the accumulation of deformations by dislocations slip during stress induced transformation, resulting in residual strains, which increase during the first cycles and tend to stabilize with saturation. The dislocations induce internal stresses that can assist the formation of stress induced martensite and, as a consequence, decrease the critical stress needed to induce martensite (Moumni et al., 2005). Conversely, the level of the reverse transformation stresses changes very little. As a consequence, the width of the hysteretic loop is significantly reduced upon cycling (Isalgue et al., 2008). As the number of cycles continue to grow the density of dislocations increases within the crystal structure. These dislocations obstruct the formation of martensite in a way similar to strain hardening in plasticity. As a consequence, the slope of the stress-strain curve increases during loading (Moumni et al., 2005).

Cumulative residual strain in $\mathrm{NiTi}$ is related to dislocations and other lattice defects, generated at high stress during the preceding loading cycle (Moumni et al., 2005; Miyazaki et al., 1986) and due to the repeated motion of the parent-martensite interface (Otsuka and Wayman, 1998), depending on the test and processing temperatures (Nemat-Nasser and Wei-Guo, 2006; Wolons et al., 1998). Cycling at higher strain rates has been found to increase the cumulative residual strain and to cause a more rapid decline of the critical stress for martensite formation (Nemat-Nasser and Wei-Guo, 2006; Strnadel et al., 1995). It has also been shown that with the same number of cycles, the residual strain increases with strain amplitude (Wang et al., 2008; Wolons et al., 1998).

The stability of the superelastic behavior may be improved by raising the critical stress for slip. Thermomechanical heat treatments aimed to stabilize the superelastic behavior of NiTi have been found effective (Miyazaki et al., 1986), minimizing cumulative residual strain and avoiding the modification of the hysteretic cycle. A thermal heat treatment promoting grain growth in $\mathrm{CuAlBe}$ wires has allowed to develop a strain close to $4.5 \%$ without cumulative residual strain on cycling (Sepulveda et al., 2007). In practice, SMAs are repeatedly deformed to obtain a stable superelastic behavior in a process that is usually called the "training process". In general, repeated training results in smaller dissipated energy for SMAs (Nemat-Nasser and WeiGuo, 2006; Strnadel et al., 1995).

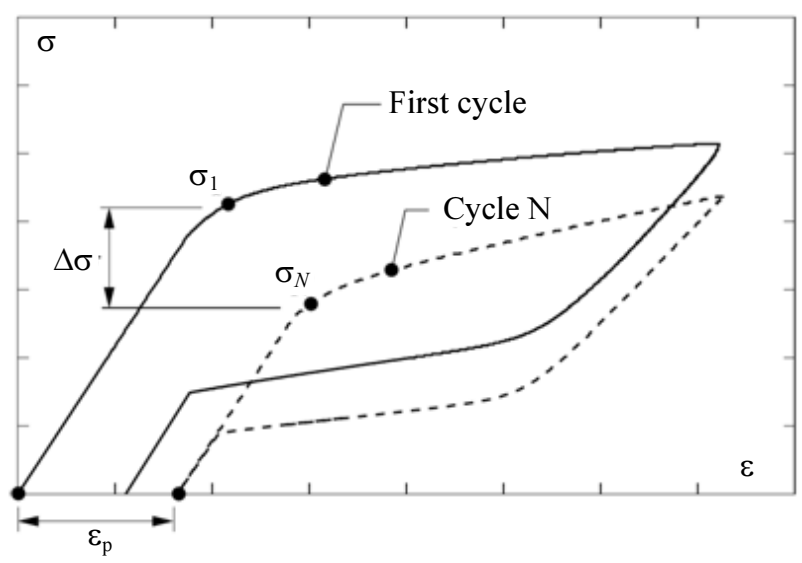

Fig. 1: Key parameters defining the cyclic instability process $\left(\varepsilon_{\mathrm{p}}\right.$ and $\left.\Delta \sigma\right)$

Several constitutive-models for SMAs are available in the literature which take into account the instability effects due to cyclic loading. They usually result from modifications in existing phenomenological models, in which the cumulative residual strain and the transformation starting temperatures $M_{s}$ and $A_{s}$, under stress-free conditions, are described as functions of the number of cycles, $n$ (Sun and Rajapakse, 2003; Tobushi et al., 1992; Saint-Sulpice et al., 2009). These functions depend on material coefficients that are greatly affected by the composition and processing conditions of the material, as well as by the nature of the cyclic loading-unloading process itself. In these models, the complex cyclic behavior of SMAs is simplified by considering these coefficients as constants (Tobushi et al., 1992), generally obtained through the observation of experimental cyclic instability curves.

The present paper addresses the influence of strain-rate and ambient temperature on the material coefficients controlling the instability functions associated with the cycling loading of austenitic NiTi, providing an additional insight into the dynamic behavior of these alloys. The study comprises a set of experimental uniaxial tensile tests, performed under a prescribed range of ambient temperatures and strainrates. This allows the definition of the material coefficients controlling the cyclic instability functions in terms of strain-rate and ambient temperature. A numerical implementation of a constitutive-model for SMAs, taking into account cumulative residual strain and the variation of the critical stress needed to induce martensite, is also presented. This model simulates the instability phenomena associated with superelastic cycling in NiTi wires, under a range of prescribed loading scenarios. This can be a very important tool in the design of vibration mitigation devices based on superelastic kernel components, namely in the seismic retrofitting of civil engineering structures. 


\section{Materials and Experimental Methods}

NiTi alloys used in this study were obtained from Euroflex GmbH. Straight, oxide-free, austenitic wire samples, with a $2.40 \mathrm{~mm}$ diameter circular cross section were selected. The chemical composition of the alloy, according to the material specifications presented by the supplier, is Ni $54.5 \mathrm{wt} . \% \mathrm{Ti}$.

\section{Tensile Tests}

A series of uniaxial tensile tests were conducted on a Zwick/Roell Z050 electro-mechanical testing machine operating in axial strain control, equipped with a W91255 temperature controlled chamber, as shown in Fig. 2(a) and (b). The clamps and the extensometers used to measure the sample strains are show in Fig. 2(c). Two T-type thermocouples (Copper-Constantan), with a temperature reading range of -40 to $100^{\circ} \mathrm{C}$, are used to monitor the temperature of the NiTi wires during cycling and the ambient temperature, connected to a National Instruments (NI) SCXI-1112 8-Channel Thermocouple Input Module. The thermo-couple is placed at the midsection of the NiTi wires, as shown in Fig. 2(d). The length of the wire specimens, between the clamps, was kept at $120 \mathrm{~mm}$ and the strain introduced in the NiTi wires amounted to $6 \%$ of their initial length, corresponding to approximately the full extent of the martensitic transformation, in the superelastic range. Experiments were conducted in both quasi-static and dynamic conditions for As-Received (AR) (Type-1) and previously stabilized NiTi specimens (Type-2). The stabilization process of the Type- 2 wire specimens comprised a set of 100 successive load-unload cycles in a AR wire with a strain-rate of $0.083 \% / \mathrm{s}$, at ambient temperature $\left(\simeq 20^{\circ} \mathrm{C}\right)$. Type- 1 specimens were used to study the instability phenomena due to cyclic loading under dynamic conditions, which are more interesting when studding the design of vibration mitigation devices based in superelastic components. The tests were performed under five different strain-rates, 0.10, 0.15, $0.20,0.25$ and $0.30 \% / \mathrm{s}$. For each strain-rate, 100 successive load-unload cycles were performed, at four ambient temperatures, 20, 30, 40 and $50^{\circ} \mathrm{C}$.

Type- 2 specimens were used to define the range of strain-rates that would be used in Type-1specimens. The influence of strain-rate on the dissipation capabilities of the NiTi wires, expressed in terms of equivalent viscous damping $\left(\zeta_{e q}=4 \pi \mathrm{E} S_{0}\right.$, with E being the energy dissipated per cycle and $S_{0}$ the maximum strain energy), during load-unload cycles was evaluated, together with the temperature variation of the specimens throughout the tests and corresponding heat transfer lag. The tests were performed at ambient temperature $(\simeq$ $20^{\circ} \mathrm{C}$ ) under three different strain-rates, $0.01,0.083$ and $0.41 \% / \mathrm{s}$. Type- 2 specimens were also used to evaluate how eventual heat transfer lags, during consecutive load-unload cycles, would influence the evolution of the temperature within the NiTi specimens.

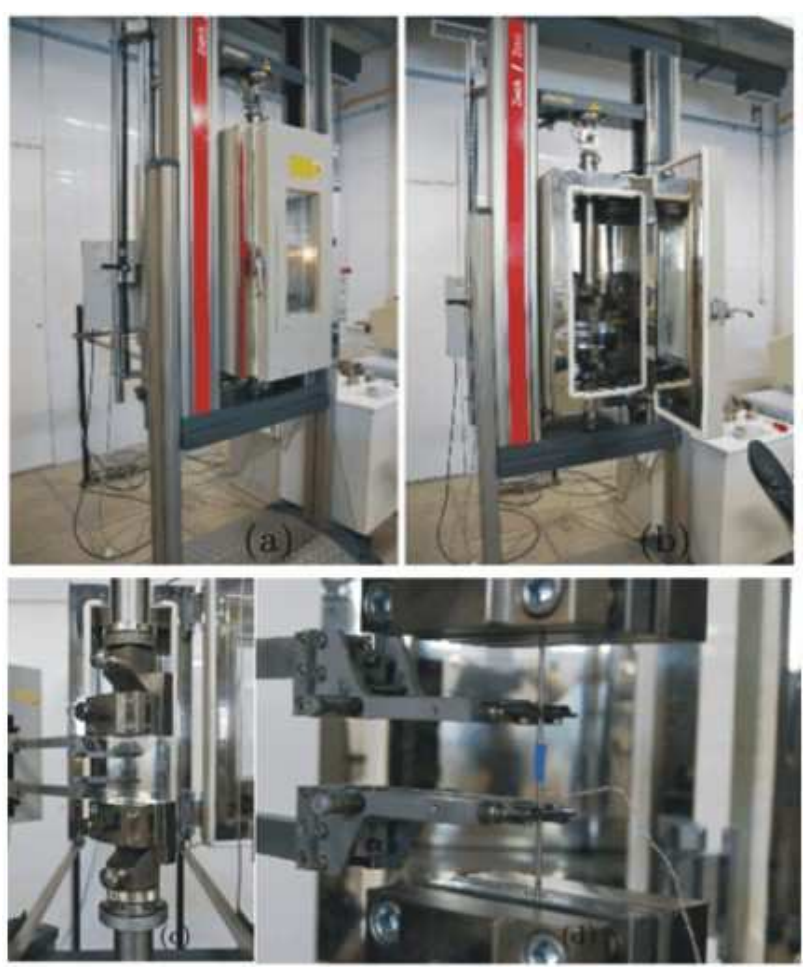

Fig. 2: Experimental equipment (a-b) testing machine and temperature controlled chamber (c-d) clamps, extensometers and thermocouple

This evaluation was carried out during 20 load-unload cycles, for strain-rates of 0.083 and $0.41 \% / \mathrm{s}$, at ambient temperature $\left(\simeq 20^{\circ} \mathrm{C}\right)$. Finally, Type- 2 specimens were used to evaluate the relation between temperature and the critical stress to induce martensitic transformations, which can be described by the material properties $C_{M}$ and $C_{A}$. These are the Clausius-Clapeyron coefficients for the forward and the inverse transformations. These values represent the slope $(\mathrm{d} \sigma / \mathrm{dT})$ of the lines defining the boundaries of the SMA transformation strips. The experimental procedure used to compute $C_{M}$ and $C_{A}$ was based on the determination of the critical transformation stresses for a set of different ambient temperatures, as described in (Isalgue et al., 2008).

\section{Differential Scanning Calorimetry}

In order to characterize the phase transformation temperatures of Type-2 wire specimens, a Differential Scanning Calorimetry (DSC) test was performed, using a SETARAM-DSC92 thermal analyzer. The temperature program comprised a thermal cycle where the sample, tested $\mathrm{AR}$, was heated up to $80^{\circ} \mathrm{C}$, held at this temperature for $6 \mathrm{~min}$ and then cooled to $-80^{\circ} \mathrm{C}$, with heating and cooling rates of $7.5^{\circ} \mathrm{C} / \mathrm{min}$. Prior to the DSC experiment, the sample was submitted to a chemical etching (10 vol.\% $\mathrm{HF}+45$ vol. $\% \mathrm{HNO}_{3}+45$ vol. $\% \mathrm{H}_{2} \mathrm{O}$ ) in order to remove the oxide and the layer formed by the cutting operation. A 
baseline analysis of the resulting curves from the DSC analysis allowed to identify the four transformation temperatures of the alloy, i.e., $M_{f}=-65^{\circ} \mathrm{C}, M_{s}=-50^{\circ} \mathrm{C}$, $A_{s}=-15^{\circ} \mathrm{C}$ and $A_{f}=7^{\circ} \mathrm{C}$.

\section{Results and Discussion}

\section{Strain-Rate Variation in Stabilized NiTi Specimens}

When a body is at a different temperature than its surroundings, heat transfer occurs in such a way that the body and the surroundings reach a thermal equilibrium. Convection is usually the dominant form of heat transfer in liquids and gases. During the cyclic deformation of a SMA specimen, self-heating depends on the balance between the total generated energy (enthalpy of transformation and internal friction) and the dissipated energy by heat transfer. The rate of the dynamic loading clearly influences the temperature variation of a NiTi specimen during a dynamic loading. For quasi-static loading conditions, the heat exchanges between the material and its surrounding environment generates almost isothermic processes. When the rate of the dynamic loading increases, the total amount of generated energy per unit time increases accordingly. As the dissipation capacity of the thermo-mechanical system is limited by the heat convection mechanism, for fast dynamic cycling, the generated and the dissipated energy become unbalanced, causing the temperature of the specimen to change as well as the shape of the hysteretic loop. As the rate of the dynamic loading increases, the system behavior becomes closer to adiabatic (Vitiello et al., 2005). The results from the tensile tests in Type-2 specimens, regarding the strainrate variation study, are presented in Fig. 3.

It is possible to observe that, when passing from quasi-static conditions to dynamic ones, important changes occur in the temperature time-history of the wires and in the shape of the corresponding hysteretic loops. For $\dot{\varepsilon}=0.01 \% / \mathrm{s}$, the temperature variation during the whole procedure is almost negligible, only amounting to approximately $2^{\circ} \mathrm{C}$. At the end of the tensile test, there is no heat transfer lag and $\zeta_{e q}$ is approximatively $7 \%$. As the strain-rate increases to $0.083 \% / \mathrm{s}$ the temperature in the wire rapidly rises to $35^{\circ} \mathrm{C}$, during loading. During unloading, there is a significant heat transfer lag, with the temperature of the wire reaching $15^{\circ} \mathrm{C}$ at the end of the mechanical cycle. Regarding the shape of the hysteric loop, both the loading and unloading plateaus become steeper than in the quasi-static situation, as $\zeta_{e q}$ rises to $8 \%$. When the strain-rate further increases to $0.41 \%$ / the temperature of the wire at the end of the loading process reaches $40^{\circ} \mathrm{C}$. At the end of the unloading process, the temperature of the wire is $19^{\circ} \mathrm{C}$.
The maximum stress level of the hysteresis continues to rise, as the loading and unloading plateaus grow steeper and $\zeta_{e q}$ decreases to about $6 \%$.

\section{Influence of Cycling Loading on the Temperature of Stabilized NiTi Specimens}

In Fig. 4 are presented the temperature time-histories for 20 consecutive load-unload cycles on Type-2 specimens. Analyzing the plots in Fig. 4, one can observe that during successive mechanical cycling, higher strain-rates cause both higher temperature variations and higher maximum temperatures in the NiTi specimen. For the tested strain-rates, the temperature of the wires follow the same general pattern, eventually stabilizing around a given value, which grows with the strain-rate. This means that within the proposed range of strain-rates the convective heat transfer process becomes rapidly balanced. This is quite important because if the temperature of the wire were to become unbounded with cycling, that would highly affect the instability phenomena under consideration. The proposed range of strain-rates is wide enough to significantly change the shape of the superelastic hysteresis, clearly affecting the energy dissipation capabilities of the material, while keeping the temperature within the NiTi wires bounded throughout the cycling process.

\section{Degradation Due to Cyclic Loading in as-Received NiTi Specimens}

The results obtained form the experimental cyclic tests in Type-1 specimens are represented as forcedeformation diagrams in Fig. 5. Analyzing the graphs in Fig. 5, one can see that during the cyclic loading of the NiTi specimen, the starting point of the stress-strain diagrams tends to deviate, in a process of cumulative residual strain. One can also see that with cyclic loading, the critical stress to induce martensite decreases, whereas the maximum stress at the end of the forward transformation is not significantly influenced. As a consequence, the slope of the stress-strain curve, during the forward transformation, increases with cycling. Regarding the stress level associated with the reverse transformation, one does not observe significant variations related with cyclic loading. These changes in the mechanical hysteresis cause a significant reduction of the area of the hysteretic loop upon cycling. According to the obtained stress-strain graphs, strain-rate and ambient temperature influence the instability of the hysteresis during cycling. For all the cyclic tests reported in section 2, the cumulative residual strain and the critical stress to induce martensite are recorded and plotted in Fig. 6 and 7. 


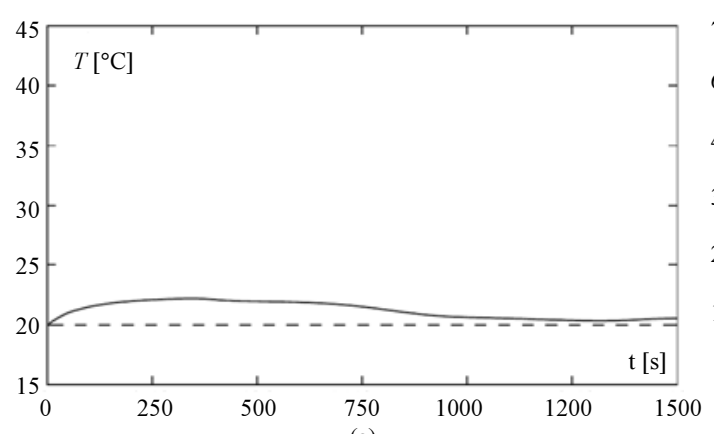

(a)

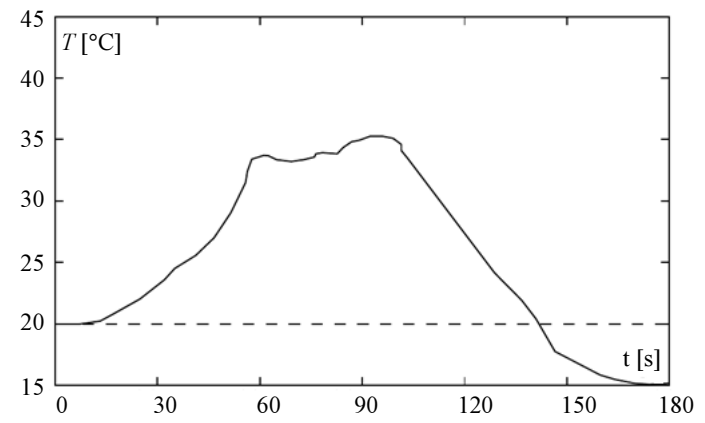

(c)

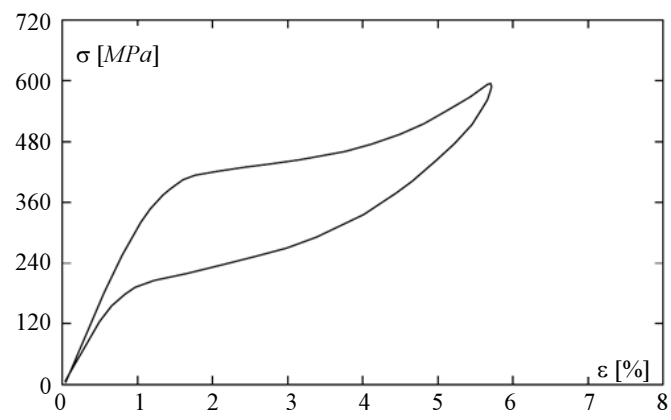

(e)

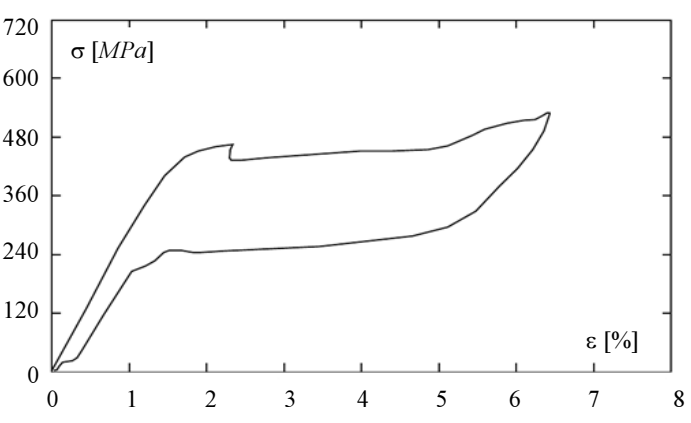

(b)

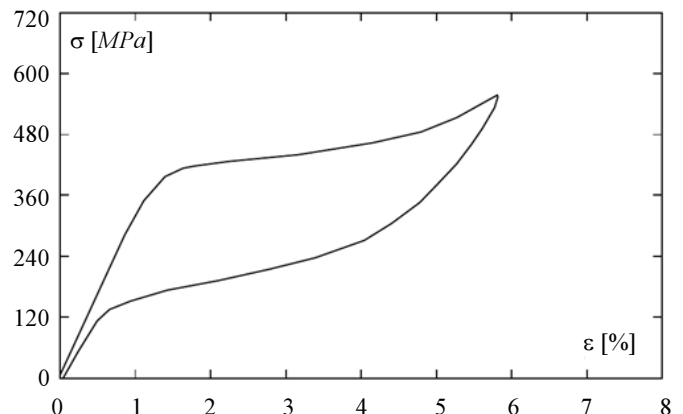

(d)

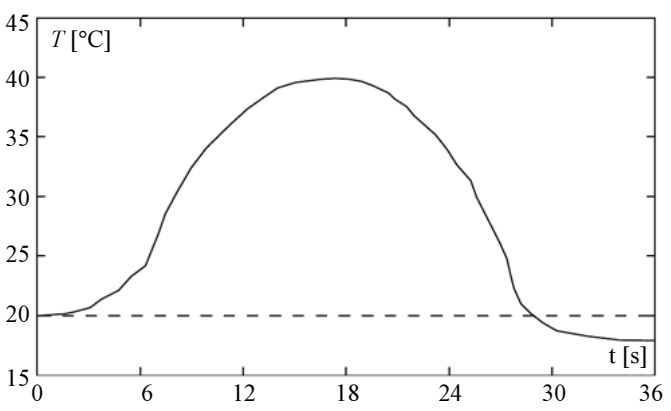

(f)

Fig. 3: (a) Temp. time-history ( $\dot{\varepsilon}=0.01 \% / \mathrm{sec})$ (b) Stress-strain diagram $(\dot{\varepsilon}=0.01 \% / \mathrm{sec})$ (c) Temp. time-history $(\dot{\varepsilon}=0.083 \% / \mathrm{sec})(\mathrm{d})$ Stress-strain diagram $(\dot{\varepsilon}=0.083 \% / \mathrm{sec})(\mathrm{e})$ Stress-strain diagram $(\dot{\varepsilon}=0.41 \% / \mathrm{sec})$ (f) Temp. time-history $(\dot{\varepsilon}=0.41 \% / \mathrm{sec})$ Self heating on mechanical cycling for different strain-rates $\left(T_{0}=20^{\circ} \mathrm{C}\right)$. Temperature time-histories and stress-strain diagrams

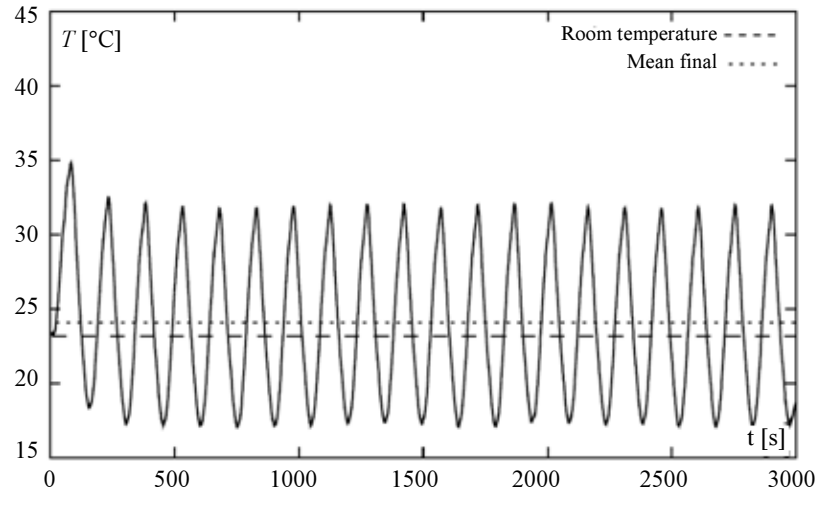

(a)

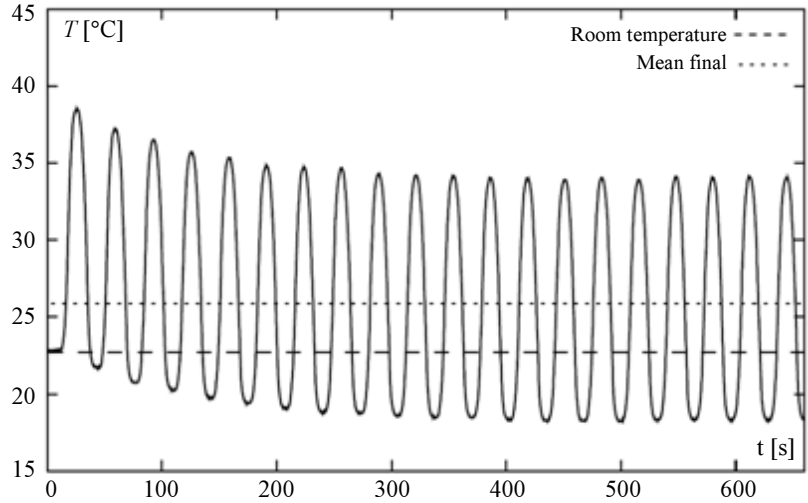

(b)

Fig. 4: (a) Cyclic loading at $(\dot{\varepsilon}=0.083 \% / \mathrm{sec})(\mathrm{b})(\dot{\varepsilon}=0.41 \% / \mathrm{sec})$ Experimental cyclic tensile tests. Temperature time-history 
Filipe Amarante dos Santos et al. / International Journal of Structural Glass and Advanced Materials Research 2018, Volume 2: 82.95 DOI: 10.3844/sgamrsp.2018.82.95

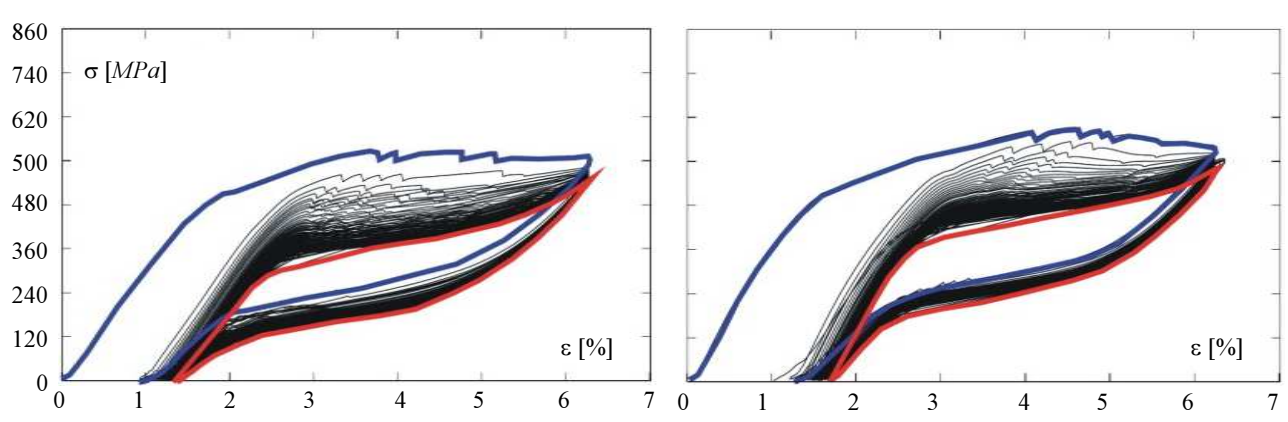

(a)

(b)

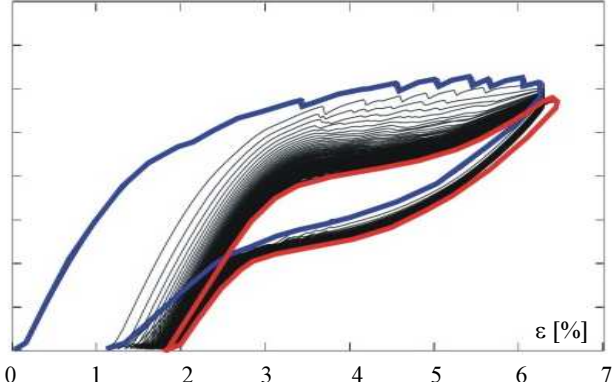

(c)

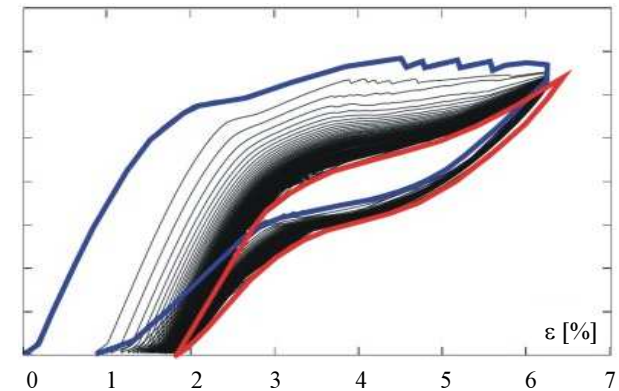

(d)

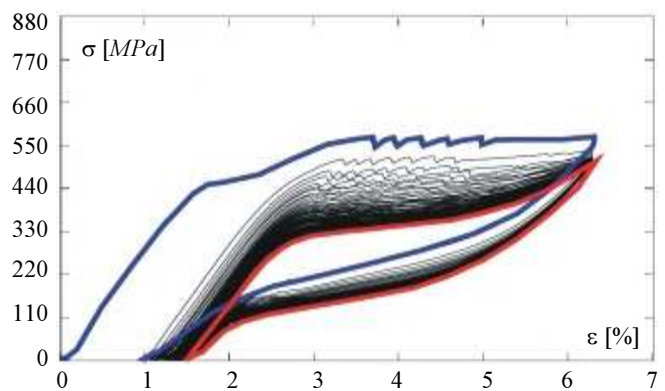

(e)

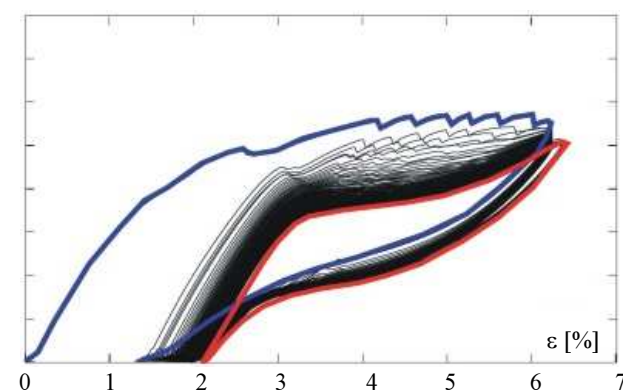

(f)

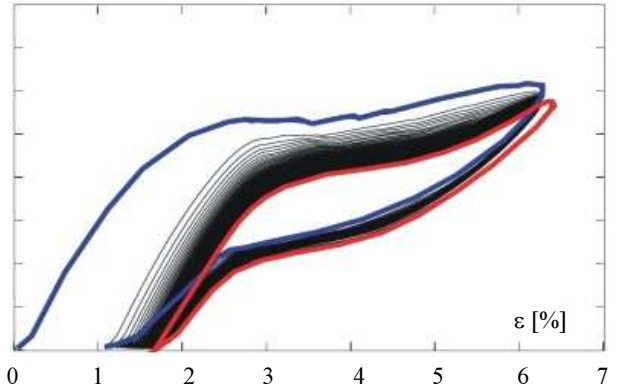

(g)

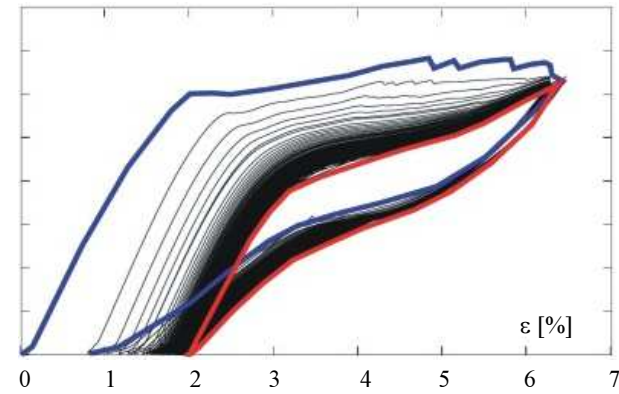

(h)

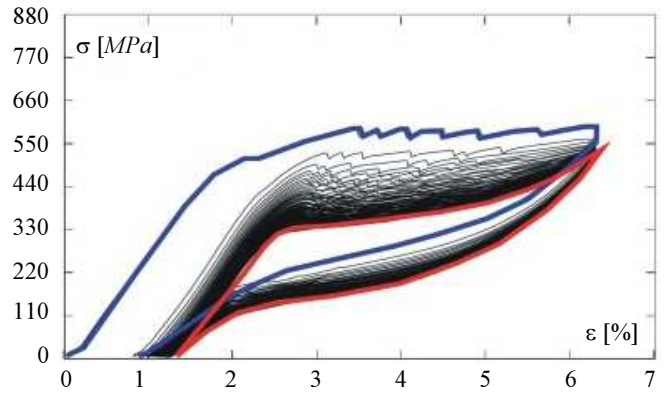

(i)

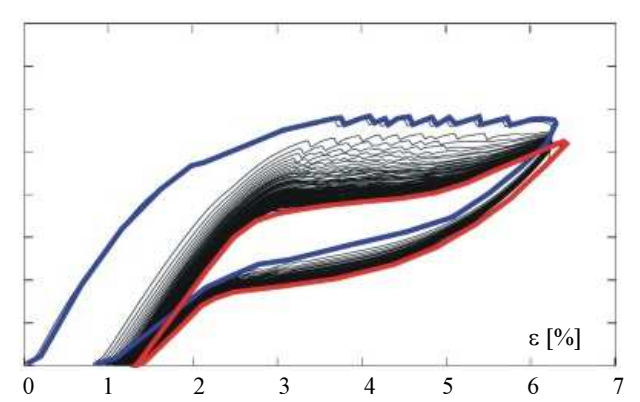

(j) 


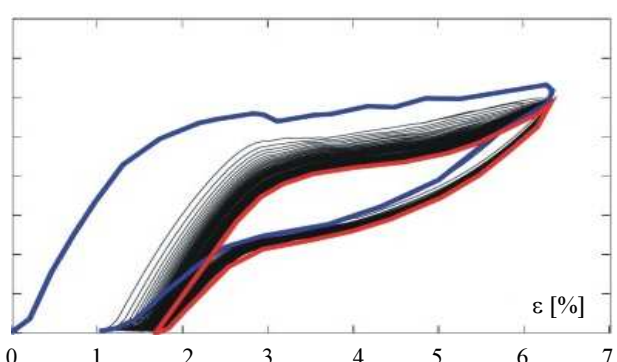

(k)

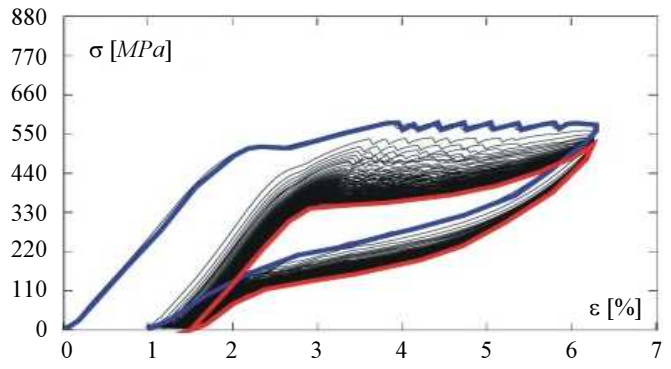

(m)

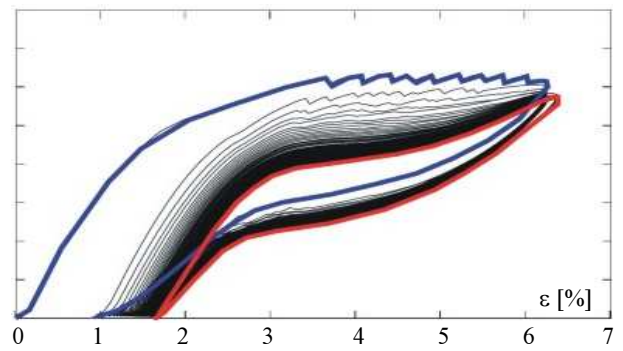

(o)

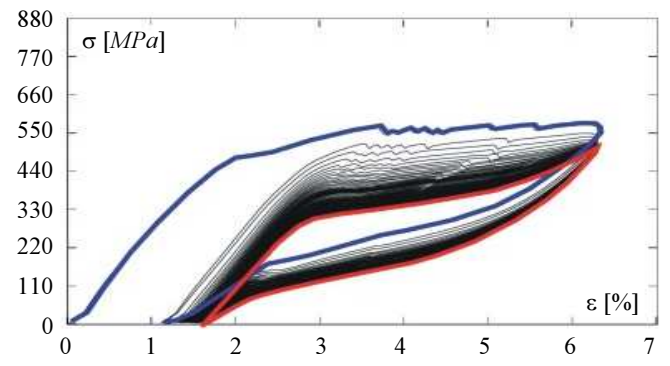

(q)

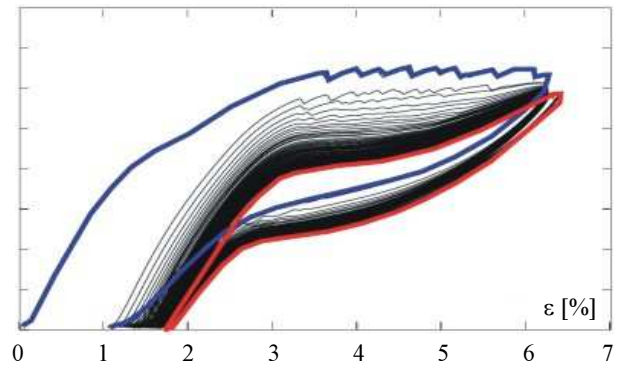

(s)

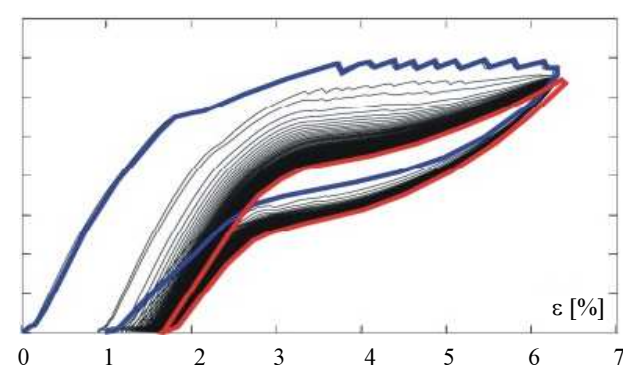

(1)

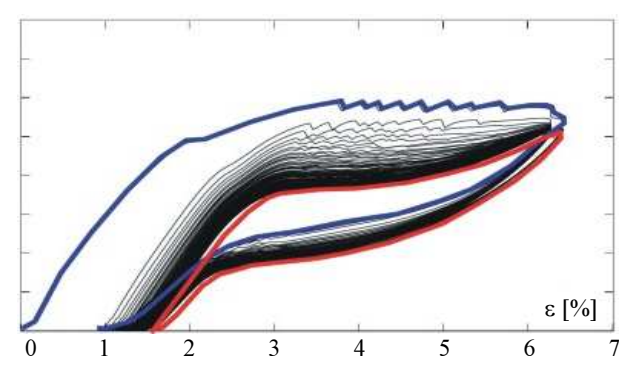

(n)

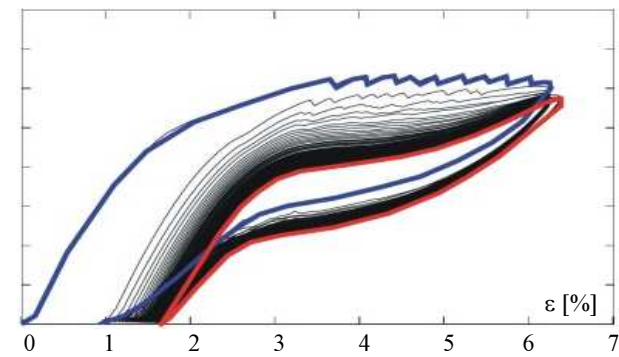

(p)

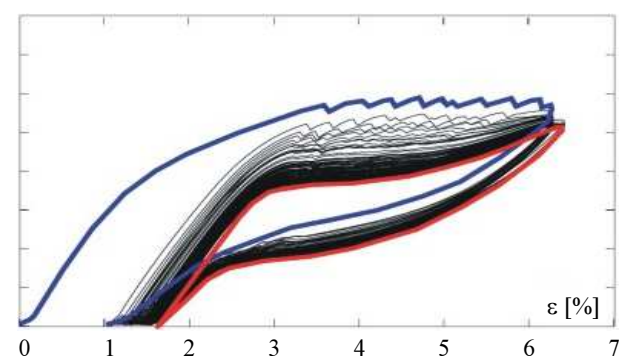

(r)

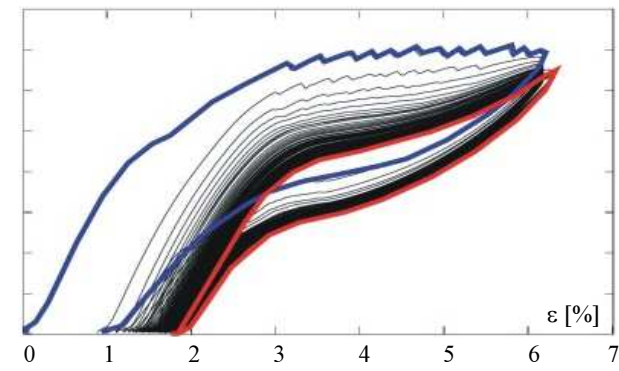

(t)

Fig. 5: (a) $20^{\circ} \mathrm{C} ; 0.10 \% / \mathrm{sec}$ (b) $30^{\circ} \mathrm{C} ; 0.10 \% / \mathrm{sec}$ (c) $40^{\circ} \mathrm{C} ; 0.10 \% / \mathrm{sec}$ (d) $50{ }^{\circ} \mathrm{C} ; 0.10 \% / \mathrm{sec}$ (e) $20{ }^{\circ} \mathrm{C} ; 0.15 \% / \sec (\mathrm{f}) 30{ }^{\circ} \mathrm{C} ; 0.15 \% / \mathrm{sec}$ (g) $40^{\circ} \mathrm{C} ; 0.15 \% / \mathrm{sec}$ (h) $50^{\circ} \mathrm{C} ; 0.15 \% / \mathrm{sec}$ (i) $20^{\circ} \mathrm{C} ; 0.20 \% / \mathrm{sec}$ (j) $30^{\circ} \mathrm{C} ; 0.20 \% / \mathrm{sec}$ (k) $40^{\circ} \mathrm{C} ; 0.20 \% / \mathrm{sec}$ (l) $50{ }^{\circ} \mathrm{C} ; 0.20 \% / \mathrm{sec}$ (m) $20^{\circ} \mathrm{C} ; 0.25 \% / \mathrm{sec}(\mathrm{n}) 30^{\circ} \mathrm{C} ; 0.25 \% / \mathrm{sec}(\mathrm{o}) 40^{\circ} \mathrm{C} ; 0.25 \% / \mathrm{sec}$ (p) $50^{\circ} \mathrm{C} ; 0.25 \% / \mathrm{sec}$ (q) $20^{\circ} \mathrm{C} ; 0.30 \% / \mathrm{sec}(\mathrm{r}) 30^{\circ} \mathrm{C} ; 0.30 \% / \mathrm{sec}$ (s) $40^{\circ} \mathrm{C} ; 0.30 \% / \mathrm{sec}$ (t) $50^{\circ} \mathrm{C} ; 0.30 \% / \mathrm{sec}$ Force-displacement diagrams associated with the cyclic loadings, for the tested strain-rates and ambient temperatures 


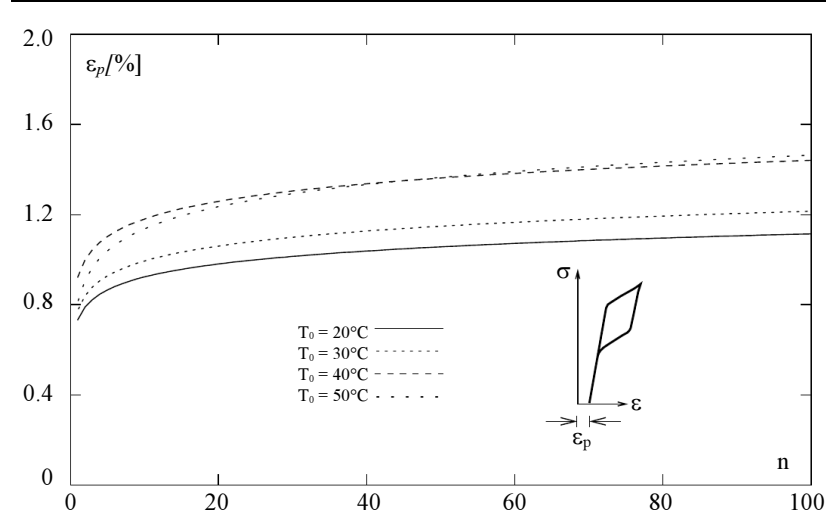

(a)

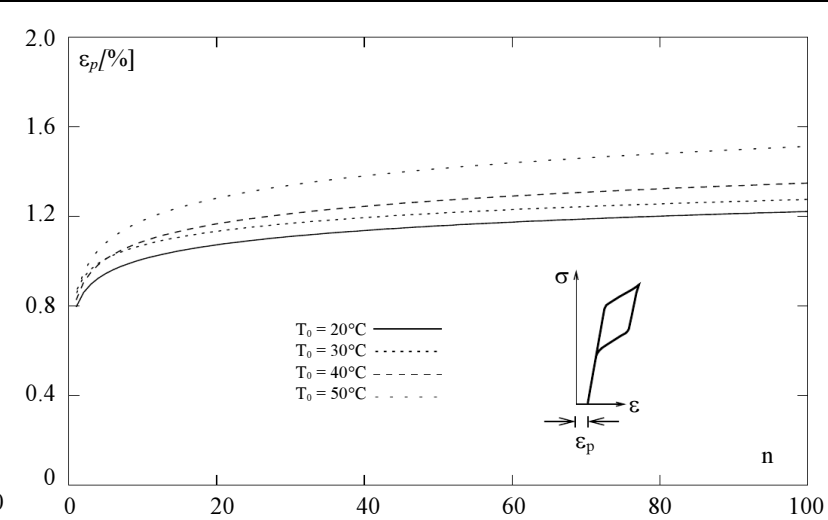

(b)

Fig. 6: (a) $\dot{\varepsilon}=0.10 \% / \mathrm{sec}$ (b) $\dot{\varepsilon}=0.30 \% / \mathrm{sec}$ Evolution of the cumulative residual strain due to cycling

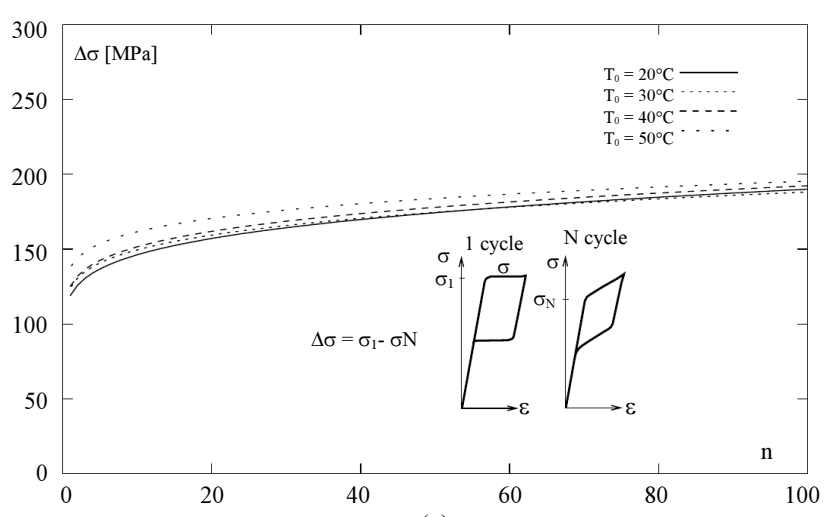

(a)

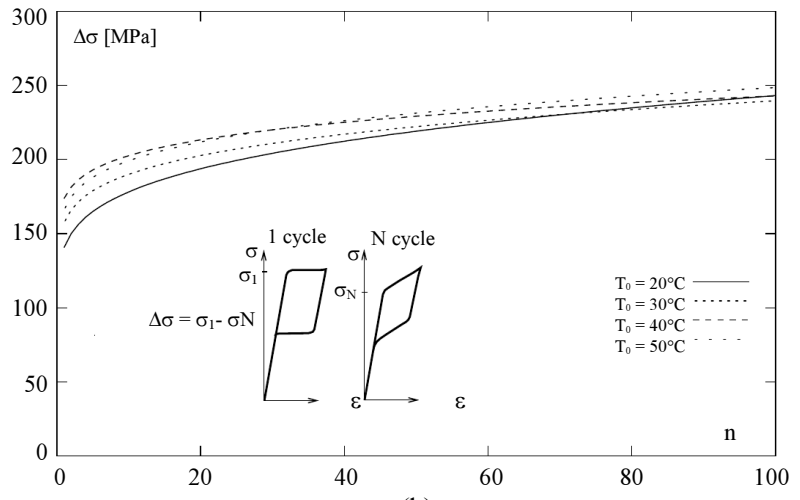

(b)

Fig. 7: (a) $\dot{\varepsilon}=0.10 \% / \mathrm{sec}$ (b) $\dot{\varepsilon}=0.30 \% / \mathrm{sec}$ Evolution of the variation of the critical stress to induce martensite

Observing Fig. 6 and 7 it is possible to confirm that the instability effects under analysis are quite important, but tend to gradually stabilize with cycling. This stabilization is faster in the case of the cumulative residual strain, $\varepsilon_{\mathrm{p}}$, which reaches a maximum value of $1.5 \%$, for $n=100$. The maximum variation of the critical stress to induce martensite, $\Delta \sigma$, is about $240 \mathrm{MPa}$. It can also be observed that, for a given number of cycles and for a given strain-rate, instability increases with ambient temperature. This may be explained by the fact that instability effects due to cycling in SMAs are usually related to dislocations and other lattice defects, generated at high stress during the preceding loading cycle. With higher ambient temperatures, the stresses needed to induce martensite are also higher, leading to a higher instability of the alloy. However, ambient temperature seems to have more influence in the net accumulated residual strain of the alloy rather than in the total variation of the critical stress to induce martensite. Regarding the strain-rate of the cyclic loading, it is possible to observe that, for a given number of cycles and for a given ambient temperature, instability increases with the strain-rate. This may also be explained by the fact that higher strain-rates yield higher stresses in the alloy, leading to higher instability due to cycling. One can also observe that $\varepsilon_{p}$ is more influenced by ambient temperature whereas $\Delta \sigma$ is more influenced by the strain-rate of the cyclic loading. This can be easily observed in Fig. 8(a) and (b), which translate the total net instability associated with $\varepsilon_{p}$ and $\Delta \sigma$, as a function of $T_{0}$ and $\dot{\varepsilon}$, for $\mathrm{n}=100$. Through the analysis of the instability curves, it is plausible to suggest that the accumulated plastic strain and the variation of the critical stress to induce martensite may be described by logarithmic functions of the type:

$\varepsilon_{p}\left(n, \dot{\varepsilon}, T_{0}\right)=a_{1}\left(\dot{\varepsilon}, T_{0}\right) \times \operatorname{In}(n)+b_{1}\left(\dot{\varepsilon}, T_{0}\right)$

and:

$\Delta \sigma\left(n, \dot{\varepsilon}, T_{0}\right)=a_{2}\left(\dot{\varepsilon}, T_{0}\right) \times \operatorname{In}(n)+b_{2}\left(\dot{\varepsilon}, T_{0}\right)$

in which $n$ is the number of cycles, $b_{i}$, the instability associated with the first cycle and $a_{i}$, the speed of the instability phenomena. 


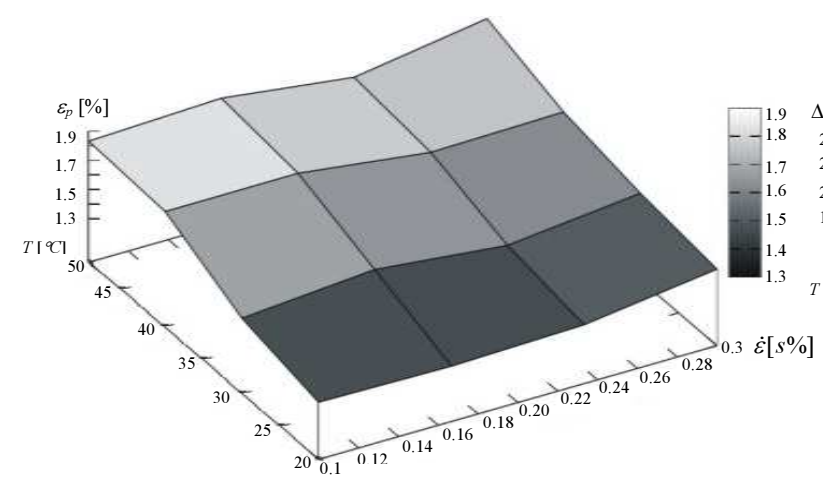

(a)

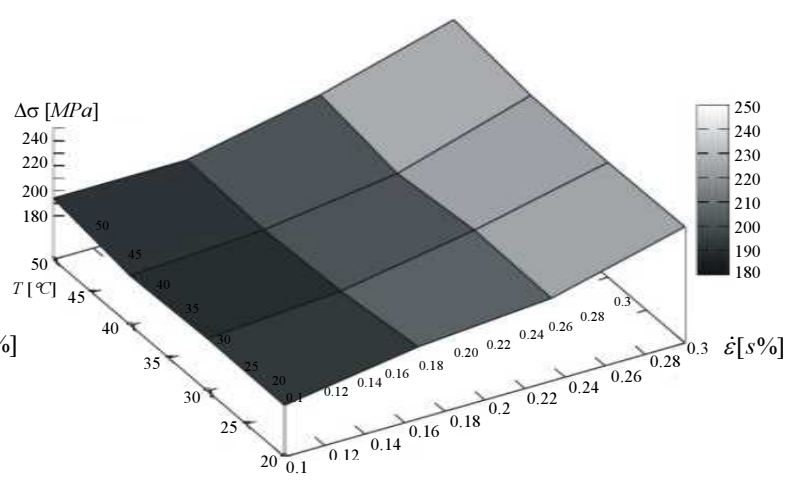

(b)

Fig. 8: (a) $\varepsilon_{p}, 100[\%]$ ( $\left.\dot{\varepsilon}\right), T_{0}$ (b) $\Delta \sigma_{100}[\mathrm{M} \mathrm{Pa}]\left(\left(\dot{\varepsilon}, T_{0}\right)\right.$ Influence of ambient temperature and strain-rate on the instability coefficients

\section{Superelastic Constitutive Model}

In order to simulate the cyclic behavior of a $\mathrm{NiTi}$ wire, with a circular cross section, a constitutive model is proposed, using a mechanical law with a parallel phase distribution coupled with exponential kinetic laws and a thermal balance equation, to apprehend the convective heat transfer problem. In order to simulate the instability phenomena observed during cycling, $\Delta \sigma$ and $\varepsilon_{p}$ are introduced in the formulation. The time evolution of the martensite fraction $\xi$ is expressed using a stress-driven exponential kinetic rule (Auricchio and Taylor, 1997), using $\beta_{A M}$ and $\beta_{M A}$ as material constants. The resulting evolution equations are given by:

$\dot{\xi}^{A M}=\beta^{A M}\left(1-\xi^{A M}\right)\left(\frac{\dot{\sigma}}{\left(\sigma-\sigma_{f}^{A M}\right)^{2}}\right)$

and:

$\dot{\xi}^{A M}=\beta^{A M} \xi^{M A}\left(\frac{\dot{\sigma}}{\left(\sigma-\sigma_{f}^{M A}\right)^{2}}\right)$

for the forward and inverse transformations, respectively. For a given temperature $T$, the starting and final stresses during the forward and inverse transformations, $\sigma_{s}^{A M}, \sigma_{f}^{M A}$ and $\sigma_{s}^{M A}, \sigma_{f}^{M A}$, respectively, may be computed using the equations that define the boundary lines of the corresponding transformation strips, i.e.,:

$\sigma_{s}^{A M}\left(n, \dot{\varepsilon}, T_{0}\right)=C_{M}\left[T-M_{s}\left(n, \dot{\varepsilon}, T_{0}\right)\right] \sigma_{f}^{A M}=C_{M}\left(T-M_{f}\right)$

$\sigma_{s}^{M A}=C_{A}\left(T-A_{s}\right) \sigma_{f}^{M A} C_{A}(T-A f)$

where:

$M_{s}\left(n, \dot{\varepsilon}, T_{0}\right)=M_{s, 0}-\frac{\Delta \sigma\left(n, \dot{\varepsilon}, T_{0}\right)}{C_{M}}$

with $M_{s, 0}$ representing the initial transformation starting temperature. The stress evolution equation is governed by Equation 7, in which, without loss of generality, $T_{0}$ is assumed to be zero (Cismasiu and Santos, 2008):

$\dot{\sigma}=E(\xi) \dot{\varepsilon}+H(\xi) \dot{\xi}+\theta \dot{T}$

where, the elastic modulus $E$ is expressed as a fraction of the martensitic elastic modulus, $E_{M}$ and of austenitic elastic modulus, $E_{A}$ :

$E(\xi)=\xi\left(E_{M}-E_{A}\right)+E_{A}$

Replacing $\dot{\sigma}$, in the transformation kinetic relations expressed by Equation 3 and 4, it yields:

$(\dot{\xi})^{A M}=\frac{\beta^{A M}\left(1-\xi^{A M}\right)(E \dot{\varepsilon}+\theta \dot{T})}{\left(\sigma-\sigma_{f}^{A M}\right)^{2}-\beta^{A M}\left(1-\xi^{A M}\right) H}$

and:

$\dot{\xi}^{M A}=\frac{\beta^{M A} \xi^{M A}(E \dot{\varepsilon}+\theta \dot{T})}{\left(\sigma-\sigma_{f}^{A M}\right)^{2}-\beta^{M} \xi^{M A} H}$

for the forward and inverse transformations, respectively, where:

$H(\xi)=\left(E_{M}-E_{A}\right)\left[\left(\varepsilon-\varepsilon_{p}\right)-\varepsilon_{L} \xi\right]-\varepsilon_{L} E(\xi)$

being $\varepsilon_{L}$ the maximum residual strain in the material. Given the presence of accumulated plastic strain, $\varepsilon_{p}$, the transformation strain range decreases by the amount of $\varepsilon_{p}$, becoming $\varepsilon-\varepsilon_{p}$. The mechanical and kinetic laws are coupled with a heat balance equation (Cismasiu and Santos, 2008), which, expressed in function of $T$, reads:

$\dot{T}=\frac{\bar{h} A\left(T-T_{0}\right)}{\rho c V}+\frac{c_{L} \dot{\xi}}{c}+\frac{\dot{W}}{\rho c}$

where, $T_{0}$ is the reference temperature of the surrounding air, $A$ is the surface area, $\mathrm{h}$ is the mean coefficient of heat 
transfer, $c_{L}$ the latent heat of transformation, $\rho$ is the density of the material, $c$ its specific heat and $\theta$ is the thermal expansion coefficient. The evolution of the dissipated energy, $W$, as the transformation proceeds can be derived from the area enclosed by partial cycles (Ortin and Delaey, 2002). The use of the Euler method enables the transformation of the time-continuous evolutionary equations into time-discrete evolutionary equations.

\section{Validation}

\section{Material Properties}

Several material parameters were characterized for the implementation of the proposed constitutive-model. In Table 1 are presented the material parameters determined according to typical values obtained in the literature (Vitiello et al., 2005); Cismasiu and Santos, 2008; Branco et al., 2012). Material parameters determined from experimental results are compiled in Table 2. The instability coefficients are presented in Table 3 and 4.

\section{Results and Discussion}

In Fig. 9 are presented a series of stress-strain diagrams yielded by the proposed constitutive-model in which the instability phenomena shown by SMAs during cyclic loading are simulated. The presented stress-strain diagrams comprise both the first and the last experimental superelastic loops, as well as the first twenty and the last numerical superelastic loops. For a better understanding of the performance of the proposed model, the numerical results are plotted against the experimental ones. Analyzing the graphs presented in Fig. 9 one may observe that the proposed constitutive-model, shows, under the prescribed testing conditions, a good overall behavior. The performance of the proposed constitutive-model can also be assessed by comparing the experimental and simulated evolution of the dissipated energy with cycling, which is shown in Fig. 10. A good correlation between the experimental and the numerical curves is observed, both revealing an important reduction of the dissipated energy with cycling. The dissipated energy associated with the last superelastic cycle $(n=100)$ only amounts to $30 \%$ of the energy dissipated in the first cycle. Translated into equivalent viscous damping this corresponds to a reduction of the damping from 17 to about $6 \%$.

Table 1: Material parameters determined from the literature

\begin{tabular}{lll}
\hline$\beta^{A M}=\beta^{\mathrm{AM}}=2 \times 10^{-6}$ & $\rho=6500 \mathrm{~kg}^{\mathrm{m}-3}$ & $C_{L}=12914 \mathrm{~J} \mathrm{Kg}$ \\
$C_{P}=500 \mathrm{~J} \mathrm{Kg}^{-1} \mathrm{~K}^{-1}$ & $\mathrm{~h}=35 \mathrm{Wm}^{-2} \mathrm{~K}^{-1}$ & $\theta=6 \times 10^{-6} \mathrm{~K}^{-1}$ \\
\hline
\end{tabular}

Table 2: Material parameters determined from the experimental results

\begin{tabular}{lll}
\hline$E_{A}=37300 \mathrm{MPa}$ & $E_{M}=21400 \mathrm{MPa}$ & $M f=-65^{\circ} \mathrm{C}$ \\
$M_{S}=-50^{\circ} \mathrm{C}$ & $A_{S}=-15^{\circ} \mathrm{C}$ & $A_{f}=7^{\circ} \mathrm{C}$ \\
$C_{M}=6.5 \mathrm{MPaK}^{-1}$ & $C_{A}=6.5 \mathrm{MPaK}^{-1}$ & $e_{L}=0.06$ \\
\hline
\end{tabular}

Table 3: Coefficients $a_{1}$ and $b_{1}$ for the quantification of $\varepsilon_{p}(\%)$

\begin{tabular}{lllllllll}
\hline$\varepsilon_{\mathrm{P}}$ & $10^{\circ} \mathrm{C}$ & & \multicolumn{2}{c}{$20^{\circ} \mathrm{C}$} & $30^{\circ} \mathrm{C}$ & & $40^{\circ} \mathrm{C}$ \\
Coef. & $a_{1}$ & $b_{1}$ & $a_{1}$ & $b_{1}$ & $a_{1}$ & $b_{1}$ & $a_{1}$ & $b_{1}$ \\
\hline $0.10 \% / s$ & 0.104 & 0.914 & 0.120 & 0.965 & 0.141 & 1.150 & 0.178 & 1.011 \\
$0.15 \% / s$ & 0.103 & 0.940 & 0.914 & 1.251 & 0.206 & 0.965 & 0.148 & 1.321 \\
$0.20 \% / s$ & 0.094 & 0.797 & 0.118 & 0.824 & 0.153 & 0.979 & 0.131 & 1.078 \\
$0.25 \% / s$ & 0.121 & 0.899 & 0.111 & 0.973 & 0.140 & 0.979 & 0.136 & 1.065 \\
$0.30 \% / s$ & 0.115 & 0.995 & 0.111 & 1.084 & 0.145 & 1.034 & 0.180 & 1.063 \\
\hline
\end{tabular}

Table 4: Coefficients a 2 and $\mathrm{b} 2$ for the quantification of $\Delta \sigma(\%)$

\begin{tabular}{|c|c|c|c|c|c|c|c|c|}
\hline \multirow{2}{*}{$\begin{array}{l}\Delta \sigma \\
\text { Coef }\end{array}$} & \multicolumn{2}{|l|}{$10^{\circ} \mathrm{C}$} & \multicolumn{2}{|l|}{$20^{\circ} \mathrm{C}$} & \multicolumn{2}{|l|}{$30^{\circ} \mathrm{C}$} & \multicolumn{2}{|l|}{$40^{\circ} \mathrm{C}$} \\
\hline & $a_{2}$ & $b_{2}$ & $a_{2}$ & $b_{2}$ & $a_{2}$ & $b_{2}$ & $a_{2}$ & $b_{2}$ \\
\hline $0.10 \% / s$ & 17.229 & 107 & 15.638 & 115 & 15.118 & 115 & 13.680 & 131 \\
\hline $0.15 \% / s$ & 21.925 & 95 & 14.897 & 116 & 14.657 & 116 & 11.764 & 132 \\
\hline $0.20 \% / s$ & 22.857 & 107 & 17.185 & 116 & 15.068 & 119 & 8.500 & 142 \\
\hline $0.25 \% / s$ & 18.436 & 125 & 21.485 & 126 & 16.565 & 137 & 17.326 & 155 \\
\hline $0.30 \% / s$ & 25.163 & 122 & 19.703 & 146 & 19.703 & 147 & 19.682 & 155 \\
\hline
\end{tabular}


Filipe Amarante dos Santos et al. / International Journal of Structural Glass and Advanced Materials Research 2018, Volume 2: 82.95 DOI: 10.3844/sgamrsp.2018.82.95

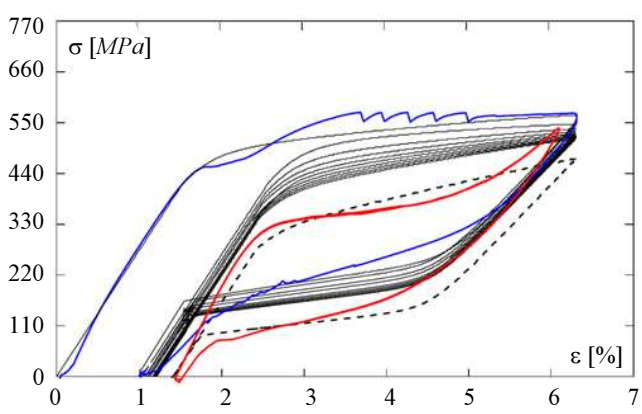

(a)

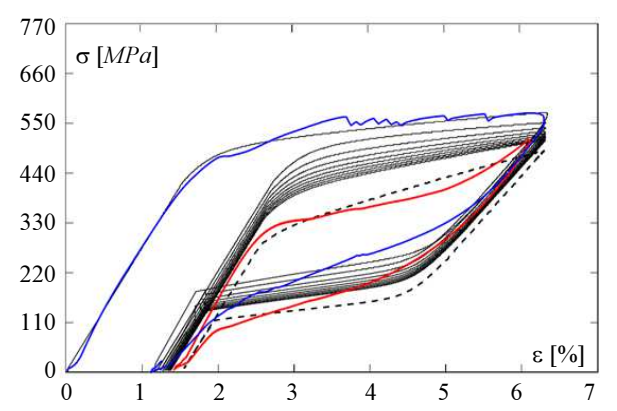

(c)

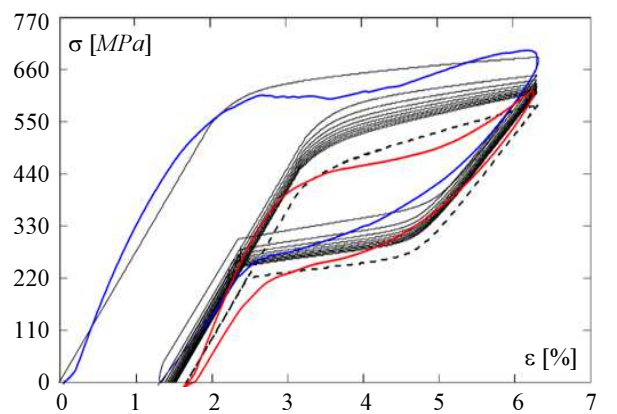

(b)

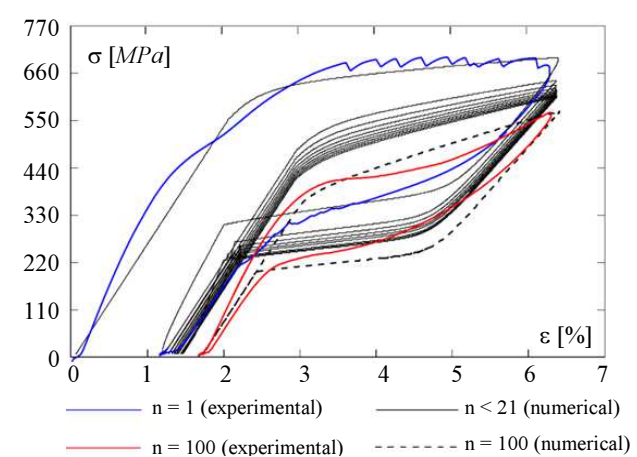

(d)

Fig. 9: (a) $T_{0}=20^{\circ} \mathrm{C}$ and $\dot{\varepsilon}=0.15 \% / \mathrm{sec}$ (b) $T_{0}=40^{\circ} \mathrm{C}$ and $\dot{\varepsilon}=0.15 \% / \mathrm{sec}$ (c) $T_{0}=20^{\circ} \mathrm{C}$ and $\dot{\varepsilon}=0.30 \% / \sec (\mathrm{d}) T_{0}=40^{\circ} \mathrm{C}$ and $\dot{\varepsilon}=$ $0.30 \% / \mathrm{sec}$ Force-displacement diagrams obtained with the implemented constitutive-model

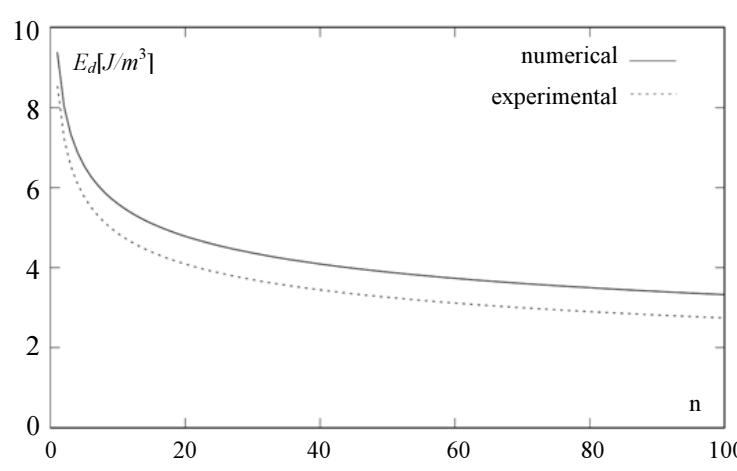

(a)

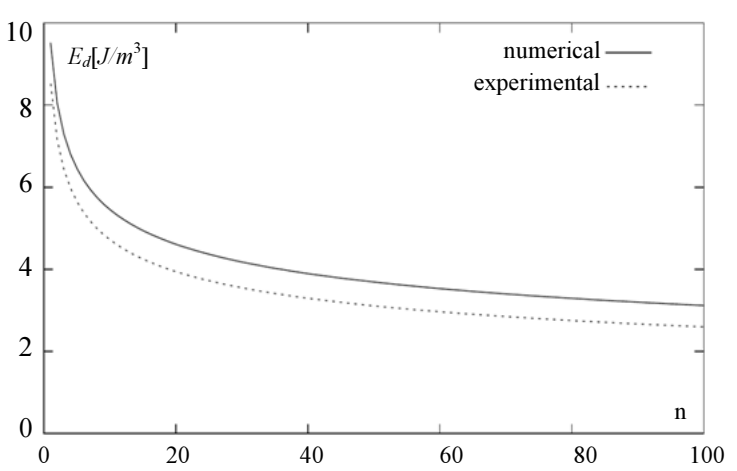

(c)

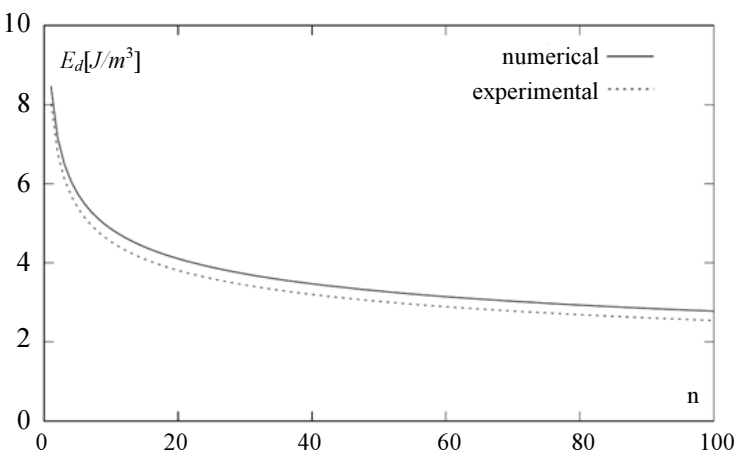

(b)

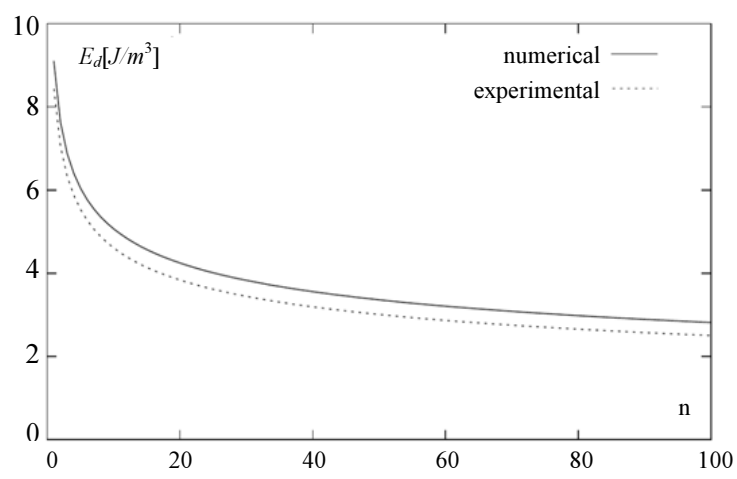

(d)

Fig. 10: (a) $T_{0}=20^{\circ} \mathrm{C}$ and $\dot{\varepsilon}=0.15 \% / \mathrm{sec}$ (b) $T_{0}=40^{\circ} \mathrm{C}$ and $\dot{\varepsilon}=0.15 \% / \mathrm{sec}$ (c) $T_{0}=20^{\circ} \mathrm{C}$ and $\dot{\varepsilon}=0.30 \% / \sec (\mathrm{d}) T_{0}=40^{\circ} \mathrm{C}$ and $\dot{\varepsilon}=0.30 \% /$ sec Evolution of the dissipated energy (Ed) with cycling 


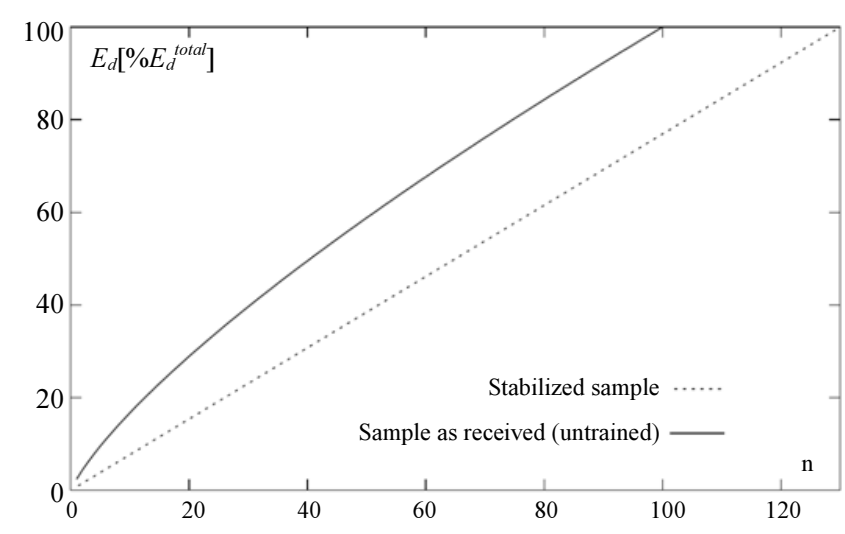

Fig. 11: Comparison between a stabilized and an untrained SMA

For seismic isolation systems re-centering is a very important feature and therefore such devices must show limited accumulation of residual strains due to cyclic loading. When SMAs are the kernel elements of these systems, the corresponding instability phenomena might hinder their performance. It has been suggested that training by deformation prior to actual service is effective for stabilizing superelasticity (Otsuka and Wayman, 1998). However this prior training causes an important reduction in the energy dissipation capabilities of the SMA material. As shown in Fig. 11, for the tested samples, a stabilized SMA has to be submitted to an additional 30 complete cycles, in order to dissipate the same amount of energy yielded by a untrained specimen. One of the most promising applications for SMAs in the seismic mitigation of civil engineering structures is their use as restraining cables in bridges Amarante dos Santos et al., 2015). The European Standard EN 1998-2 (CEN, 2005), defines the restoring capability of seismic isolation systems, which can be expressed in terms of strains as:

$$
\varepsilon_{r m} \leq \varepsilon_{m}-0.5 \varepsilon_{a, \max }
$$

where:

- $\varepsilon_{m}$ is the strain capacity of the isolation system i.e., the maximum strain that the system can sustain in the considered direction

- $\varepsilon_{r m}$ is the residual strain of the isolation system, corresponding to $\varepsilon_{m}$, i.e., the residual strain when the stress required to induce strain $\varepsilon_{m}$, is removed, under quasi-static conditions

- $\varepsilon_{a, \max }$ is the maximum value of the design strain of the isolation system, increased by 1.5

If one considers $\varepsilon_{a \text {, max }}=\varepsilon_{m}=6 \%$, one obtains $\varepsilon_{r m}=$ $1.5 \%$. Comparing this value with the maximum residual strain obtained in the experimental tensile cyclic tests one can see that these alloys still comply with the restoring capability requirements defined in EN 1998-2.

To conclude this discussion, one may say that cyclic instability phenomena in SMAs decrease their performance in seismic isolation systems, hindering both their dissipation and restoring capabilities. Even so, they are able to comply with the prescribed design requirements. The enforcement of an initial training, prior to service, in order to obtain a stabilized alloy, is not advantageous, since it is during these first cycles of stabilization that the alloy shows greater energy dissipation capabilities.

\section{Conclusion}

The results presented the characterization of the cyclic behavior of a NiTi superelastic alloy with emphasis on the definition of the instability functions associated with the cumulative residual strain and the variation of the critical stress needed to induce martensite. It was observed that, for the prescribed range of ambient temperatures and strain-rates, $\varepsilon_{p}$ is more influenced by ambient temperature whereas $\Delta \sigma$ is more influenced by the strain-rate of the cyclic loading. A constitutive-model for SMAs was also presented, which is able to successfully simulate these cyclic instability phenomena, showing an overall good performance. It is suggested that stabilization by initial training, prior to service, is not advantageous, since it is during these first cycles that the alloy shows greater energy dissipation capabilities.

\section{Acknowledgement}

The authors acknowledge Luís Pereira for his valuable contribution during the experimental tests.

\section{Author's Contributions}

Filipe Amarante dos Santos and Corneliu Cismasiu: Developed the implementation of the constitutive model for SMAs. 
Francisco Braz Fernandes: Performed the DSC analysis and contributed to the writing of the manuscript.

\section{Ethics}

The Authors declare there is not conflict of interest.

\section{References}

Andrawes, B. and R. DesRoches, 2007. Comparison between shape memory alloy restrainers and other bridge retrofit devices. ASCE J. Bridge Eng., 12: 700-709.

Auricchio, F. and R.L. Taylor, 1997. Shape-memory alloys: Modeling and numerical simulations of the superelastic behavior. Comput. Methods Applied Mechan. Eng., 143: 175-194.

Beltran, J., C. Cruz, R. Herrera and R. Moroni, 2011. Shape memory alloy $\mathrm{CuAlBe}$ strands subjected to cyclic axial loads. Eng. Structures 33: 2910-2918.

Boroschek, R.L., G. Farias, O. Moroni and M. Sarrazin, 2007. Effect of SMA braces in a steel frame building. J. Earthquake Eng., 11: 326-342.

Branco, M., L. Guerreiro, K. Mahesh and F. Braz Fernandes, 2012. Effect of load cycling on the phase transformations in NiTi wires for civil engineering applications. Construction Build. Mater., 36: 508-519.

CEN, 2005. Eurocode 8 design of structures for earthquake resistance PART 2: Bridges. Ref. No. EN 1998-2:2005: E

Cismasiu, C. and F.P.A. Santos, 2008. Numerical simulation of superelastic shape memory alloys subjected to dynamic loads. Smart Mater. Structures 17: $25-36$.

Corbi, O., 2003. Shape memory alloys and their application in structural oscillations attenuation. Simulation Modell. Practice Theory, 11: 387-402.

Croci, G., 2001. Strengthening the basilica of St. Francis of Assisi after the September 1997 Earthquake. Structural Eng. Int., 11: 207-210

DesRoches, R. and M. Delemont, 2002. Seismic retrofit of simply supported bridges using shape memory alloys. Eng. Structures, 24: 325-332.

Dolce, M. and D. Cardone, 2001. Mechanical behaviour of shape memory alloys for seismic applications 2 . Austenite NiTi wires subjected to tension. Int. J. Mechan. Sci., 43: 2657-2677. DOI: 10.1016/S0020-7403(01)00050-9

Dolce, M., D. Cardone, F.C. Ponzo and C. Valente, 2005. Shaking table tests on reinforced concrete frames without and with passive control systems. Earthquake Eng. Structural Dynamics, 34: 1687-1717.
Indirli, M., M.G. Castellano, P. Clemente and A. Martelli, 2001. Demo-application of shape memory alloy devices: The rehabilitation of the S. Giorgio Church bell-tower. SPIE Proc., 4330: 262-272.

Isalgue, A., V. Torra, A. Yawny and F. Lovey, 2008. Metastable effects on martensitic transformation in SMA Part VI. the Clausius-Clapeyron relationship. J. Thermal Anal. Calorimetry, 91: 991-998.

Johnson, R., J.E. Padgett, M.E. Maragakis, R. DesRoches and M.S. Saiidi, 2008. Large scale testing of Nitinol shape-memory alloy devices for retrofitting of bridges. Smart Mater. Structures,

Kan, 2009. Ratchetting deformation of super-elastic and shape-memory NiTi alloys. Mechan. Mater., 41: 139-153.

McCormick, J., R. DesRoches, D. Fugazza and F. Auricchio, 2006. Seismic vibration control using superelastic shape memory alloys. J. Eng. Mater. Technol., 128: 294-301.

Miyazaki, S., T. Imai and K. Otsuka, 1986. Effect of cyclic deformation on the pseudoelasticity characteristics of Ti-Ni Alloys. Metallurgical Mater. Trans. A, 17: 115-120.

Montecinos, S., M. Moroni and A. Sepulveda, 2005. Superelastic behavior and damping capacity of $\mathrm{CuAlBe}$ alloys. Mater. Sci. Eng. A, 419: 91-97.

Moumni, Z., A. Van Herpen and P. Riberty, 2005. Fatigue analysis of shape memory alloys: Energy approach. Smart Mater. Structures, 14: S287-S292.

Nemat-Nasser, S. and G. Wei-Guo, 2006. Superelastic and cyclic response of niti sma at various strain rates and temperatures. Mechan. Mater., 38: 463-474.

Ocel, J., R. DesRoches, R.T. Leon, W.G. Hess and R. Krumme et al., 2004. Steel beam-column connections using shape memory alloys. J. Structural Eng., 130: 732-740.

Ortín, J. and L. Delaey, 2002. Hysteresis in shapememory alloys. Int. J. Non-Linear Mechan., 37: 1275-1281.

Otsuka, K. and C.M. Wayman, 1998. Shape memory materials, Cambridge University Press

Padgett, J.E., R. DesRoches and R. Ehlinger, 2010. Experimental response modification of a four-span bridge retrofit with shape memory alloys. Structural Control Health Monitoring.

Patoor, E., D.C. Lagoudas, P. Entchev, C. Brinson and X. Gao, 2006. Shape memory alloys, Part I: General properties and modeling of single crystals. Mechan. Mater., 38: 391-429.

Piedboeuf, M.C. and R. Gauvin, 1998. Damping behaviour of shape memory alloys: Strain amplitude, frequency and temperature effects. J. Sound Vibration, 214: 885-901. 
Saint-Sulpice, L., S.A. Chirani and S. Calloch, 2009. A 3D super-elastic model for shape memory alloys taking into account progressive strain under cyclic loadings. Mechan. Mater., 41: 12-26.

Amarante dos Santos, F.P., C. Cismaşiu and T.J. Pamies, 2015. Semi-active vibration control device based on superelastic NiTi wires. Structural Control Health Monitoring.

Sepulveda, A., R. Muoz, F. Lovey, C. Auguet and A. Isalgue et al., 2007. Metastable effects on martensitic transformation in SMA. J. Thermal Anal. Calorimetry, 89: 101-107.

Shook, D.A., P.N. Roschke and O.E. Ozbulut, 2008. Superelastic semi-active damping of a base-isolated structure. Structural Control Health Monitoring 15: 746-768.

Strnadel, B., S. Ohashi, H. Ohtsuka, T. Ishihara and S. Miyazaki, 1995. Cyclic stress-strain characteristics of ti-ni and ti-ni-cu shape memory alloys. Mater. Sci. Eng., 202: 148-156.

DOI: $10.1016 / 0921-5093(95) 09801-1$

Sun, S. and R.K.N.D. Rajapakse, 2003. Simulation of pseudoelastic behaviour of SMA under cyclic loading. Computational Mater. Sci., 28: 663-674. DOI: 10.1016/j.commatsci.2003.08.022

Tamai, H., T.Y. Kitagawa and Fukuta, 2004. Application of SMA rods to exposed-type column bases in smart structural systems. Proceedings of the 13th World Conference on Earthquake Engineering, Aug. 1-6, Vancouver, pp: 1-15.

Tobushi, H., H. Iwanaga, K. Tanaka, T. Hori and T. Sawada, 1991. Deformation behaviour of TiNi shape memory alloy subjected to variable stress and temperature. Continuum Mechan. Thermodynamics 3: 79-93.

Tobushi, H., H. Iwanaga, K. Tanaka, T. Hori and T. Sawada, 1992. Stress-strain-temperature relations of TiNi shape memory alloy suitable for thermomechanical cycling. JSME Int. J. Series A, Solid Mechan. Material Eng., 35: 271-277.
Tobushi, H., Y. Shimeno, T. Hachisuka and K. Tanaka 1998. Influence of strain rate on superelastic properties of TiNi shape memory alloy. Mechan. Mater., 30: 141-150.

Torra, V., A. Isalgue, F. Martorell, P. Terriault and F. Lovey, 2007. Built in dampers for family homes via SMA: An ANSYS computation scheme based on mesoscopic and microscopic experimental analyses. Eng. Structures, 29: 1889-1902.

Vitiello, A., G. Giorleo and R.E. Morace, 2005. Analysis of thermo-mechanical behaviour of Nitinol wires with high strain rates. Smart Mater. Structures, 14: 215-221.

Wang, X., B. $\mathrm{Xu}$ and $\mathrm{Z}$. Yue, 2008. Phase transformation behavior of pseudoelastic NiTi shape memory alloys under large strain. J. Alloys Compounds, 463: 417-422.

Wilde, K., P. Gardoni and Y. Fujino, 2000. Base isolation system with shape memory alloy device for elevated highway bridges. Eng. Structures, 22: 222-229. DOI: 10.1016/S0141-0296(98)00097-2

Wolons, D., F. Gandhi and B. Malovrh, 1998. Experimental investigation of the pseudoelastic hysteresis damping characteristics of shape memory alloy wires. J. Intelligent Mater. Syst. Structures, 9: 116-126.

Zhang, Y. and S. Zhu, 2008. Seismic response control of building structures with superelastic shape memory alloy wire dampers. J. Eng. Mechan., 134: 240-251. DOI: 10.1061/(ASCE)0733-9399(2008)134:3(240) 